\title{
Pregnancy in patients with thalassemia intermedia: A rare case report
}

\author{
Meena $P^{1}$, Jain $S^{2}$, Lakha $V^{3}$, Rajaram $S^{4}$, Goel $\mathbf{N}^{5}$ \\ ${ }^{1}$ Dr Pragati Meena, Assitant Professor, Obst and Gynae, NIMS Medical College, Jaipur, Rajasthan, ${ }^{2}$ Dr. Sandhya Jain, \\ Assitant Professor, ${ }^{3}$ Dr. Vikas Lakha, Assistant Professor, ${ }^{4}$ Dr. Shalini Rajaram, Director \& Professor, ${ }^{5}$ Dr. Neerja Goel, \\ Director \& Professor; ${ }^{2-5}$ all authors are affiliated with Department of Obstetrics \& Gynecology, University College of \\ Medical Sciences and Guru Teg Bahadur Hospital, Delhi, India.
}

Address for Correspondence: Dr Pragati Meena, NIMS Medical College, Jaipur, Rajasthan. Address- 67, Rohini Nagar, Jagatpura, Jaipur, Rajasthan. E-mail: drpragati02@gmail.com

\begin{abstract}
Background: Annual incidence of $\beta$-thalassemia is $1 / 100,000$ throughout world. Asian countries like India, Pakistan, and Bangladesh account for $79 \%$ thalassemia births. $\beta$-thalassemia is inherited as an autosomal recessive disorder. It is most common single gene disorder, considered as most widespread genetic disease in the world. $\beta$-thalassemia intermedia is the most common cause of chronic hemolytic anemia and accounts for one-fourth of $\beta$-thalassemia cases. Case Report: Here we report a case of 22 year old woman presented to ANC clinic at our hospital, referred from private in view of primigravida with $37+3$ weeks of gestation with fetal growth restriction (FGR) with known case of hypothyroidism; there was history of splenectomy in childhood. Labor was induced in view of severe FGR and patient underwent cesarean section for nonprogress of labor with fetal distress, delivered a male child of $1.6 \mathrm{~kg}$. Her postoperative period was uneventful. She received thromboprophylaxis postoperatively and discharged in satisfactory condition. Patient was advised to review after 6 months for evaluation of baby in pediatric OPD. A multidisciplinary approach is required to manage these patients. Conclusion: Multidisciplinary team approach is required for in pregnancy with thalassemia. Strict monitoring and early management of complications can lead to optimal fetomaternal outcomes.
\end{abstract}

Keywords: Hypothyroidism, Preganancy, Thalassemia intermedia

\section{Introduction}

Clinical spectrum of $\beta$ thalassemia intermedia is lie between thalassemia major and minor. Thalassemia intermedia term was given by Reethi-Greepi-Micheli in 1955[1], they described patient as being too hematologically mild to be called major, but too hematological severe to be called minor. The absolute number of affected individuals is still unclear, however Asian countries like India, Pakistan, Bangladesh count for $79 \%$ thalassemia births. Patients with thalassemia intermedia generally have wide clinical spectrum. In mild clinical disease patient is asymptomatic until adult life whereas severe disease is usually diagnosed at the age of 2-6 years [2]. Etiology of thalassemia is based on an imbalance of globin chain synthesis, which leads to partial suppression of $\beta$ globulin protein synthesis. In $\beta$ thalassemia intermedia, imbalance is greater than $\beta$ thalassemia trait and less than thalassemia major. There are three mechanisms of mild clinical disease in thalassemia

Manuscript received: $10^{\text {th }}$ June 2016

Reviewed: $24^{\text {th }}$ June 2016

Author Corrected: $5^{\text {th }}$ July 2016

Accepted for Publication: $20^{\text {th }}$ July 2016 intermedia- Inheritance of mild $\beta^{+}$mutation, coinheritance with $\alpha$ thalassemia, mutation in Gy promoter gene with increased $\mathrm{HbF}$ [3].

Patients with thalassemia intermedia suffer from mild to moderate anemia with hemoglobin levels of 7-10 g/dl, with splenomegaly of variable degree. They survive successfully without need of regular blood transfusions [4]. They have normal growth and development and asymptomatic until adulthood and usually present with splenomegaly and anemia. Anemia is usually incidental finding during hematological examination or studies.

Women with thalassemia intermedia are usually fertile and pregnancy is possible in most of cases. Only few cases of pregnancy outcomes have been reported so far.

Because of chronic anemia in pregnancy, there are increased chances of obstetric complications i.e. spontaneous abortion, preterm labor, FGR (60\%), fetal intrauterine demise [1,2]. 


\section{Case Report}

\section{Case Report}

Here we report a case of 22 year old women who presented to antenatal clinic of our hospital, referred from private as a primigravida at 37 weeks of gestation with thalassemia intermedia with fetal growth restriction with moderate anemia; she had received 3 units of blood transfusion in same hospital. Patient's history revealed that she had splenectomy at age of 13 years, along with blood transfusion. At that time she had complaints of on and off fever since 15 days, weakness and pain in lower limbs since 15 days. She had history of similar episodes intermittently since 2 years of age. (Table 1)

Table-1: The following investigations clinched the diagnosis of thalassemia.

\begin{tabular}{|c|c|}
\hline $\mathrm{Hb}(\mathrm{g} / \mathrm{dl})$ & 8.4 \\
\hline $\mathrm{TLC}\left(/ \mathrm{mm}^{3}\right)$ & 9600 \\
\hline $\mathrm{DLC}$ & $\mathrm{P}_{60} \mathrm{~L}_{40} \mathrm{M}_{0} \mathrm{E}_{0}$ \\
\hline Platelet count $\left(/ \mathrm{mm}^{3}\right)$ & 3 \\
\hline Peripheral smear & $\begin{array}{c}\text { RBC showing marked anisocytosis, microcytic } \\
\text { hypochromic, no parasite seen }\end{array}$ \\
\hline Hb chromatography & 27.4 \\
\hline Hb-F (normal $<1.5)$ & 7.0 \\
\hline Hb-A2 (normal $<3.5)$ & Normal \\
\hline Liver function tests & \\
\hline
\end{tabular}

Diagnosis was made by clinical features and laboratory findings. She underwent splenectomy in view of splenomegaly with fever. Her Postoperative period was uneventful; she improved and was discharged after 2 weeks.

Patient was induced with cerviprime gel in view of FGR followed by emergency cesarean in view of failed induction with fetal distress. She delivered a healthy $1.6 \mathrm{Kg}$ baby with Apgar score 10/10. She received thromboprophylaxis and her post operative period was eventful. Baby was transferred to NICU for further evaluation, and discharged with advice of review after 6 month for hematological investigations.

\section{Discussion}

$\beta$ Thalassemia intermedia is an autosomal recessive disorder or hemoglobinopathy which is characterized by absent or deficient synthesis of $\beta$ globulin chains. Patients with thalassemia intermedia encompass a very wide clinical spectrum of disease manifestations e.g. mild disease similar to thalassemia trait and with severe disease similar to thalassemia major. Etiology - Imbalance in globin chain synthesis is greater then thalassemia trait but lesser than $\beta$ thalassemia major. Milld clinical symptoms of thalassemia intermedia explained by various mechanism .

$\checkmark$ Mild $\beta^{+}$mutation inheritance

$\checkmark$ Increase HBF level associated with mutation in $\mathrm{G}_{\gamma}$-promotor gene encoding enzyme $\mathrm{X}_{\mathrm{mn}-1}$.

Pathophysiology - Various factors are responsible for clinical menifestations-

1. Ineffective erythropoiesis- This is primary determinant of anemia

2. Iron overload

3. Chronic anemia

Molucular defects in beta globin chain synthesis, Causes imbalance in $\alpha$ (Excess and free)/ $\beta$ globin chain ratio

1. Excess $\alpha$ chains which are highly unstable precipitates into erythroid precursors in bone marrow causing oxidative damage to RBC membrane, loss of Flip-Flop mechanism that leads to ineffective erythropoiesis that causes Free radical injury and iron overload, Endocrine complication and thrombosis due to decreased protein C \& S.

2. Hemolysis of immature RBC leads to anemia, tissue hpoxia, RBC degradation, FGR. Erythroid bone marrow expension leads to cortical bone thinning and pathological fracture, deformities. Hepatoslenomegaly and jaundice is present due to hemolysis [5]. 
One or both parents are a typical carrier, with high $\mathrm{HbF}$ and border line $\mathrm{HbA} 2$. Oliveri NF et al reported that increase $\mathrm{HbF}$ level associated with increase HbA level, balance globin chain synthesis that improve clinical status of patient [6,7]. Few case series have demonstrated favourable maternal and fetal outcome in patients with $\beta$ Thalassemia intermedia when patients were monitored closely.

Physiological hemodynamic changes in pregnancy like hemodilution are aggravated in thalassemia. Cardiovascular system get worse in these patients, however they had normal ECG and tolerate pregnancy. Increase iron overload in non transfusion dependent thalassemia intermedia patient due to ineffective erythropoiesis,increased dietary iron absorption, rapid plasma iron turnover. More than $60 \%$ pregnancies with Thalassemia intermedia are complicated with intrauterine growth restriction it is due to anemia induced hypoxia, splenomegaly interfere with uterus enlargement. Thromboembolic events increase during pregnancy due to dysregulation of nitric oxide homeostasis due to hemolytic process that leads to thrombosis and pulmonary hypertension. Multiple transfusions are needed in most cases during pregnancy, even in non-transfusion dependent patients. (Table 2)

Table-2: The following table depicts the hematological parameters for the diagnosis of Thalassemia intermedia-

\begin{tabular}{|c|c|c|}
\hline Parameter & Th. Intermedia & Normal range \\
\hline $\mathrm{Hb}(\mathrm{gm} / \mathrm{dl})$ & $<7-8 \mathrm{gm} / \mathrm{dl}$ & $12-14 \mathrm{gm} / \mathrm{dl}$ \\
\hline Hct $\%$ & Reduced & $36-44 \%$ \\
\hline RDW & Normal & \\
\hline RBC count & $>5.5$ million & 3-5 million/dl \\
\hline $\mathrm{MCV}$ & $<80 \mathrm{fl}$ & $80-97 \mathrm{fl}$ \\
\hline $\mathrm{MCHC}$ & Normal & $32-36 \%$ \\
\hline $\mathrm{MCH}$ & $<27 \mathrm{pg}$ & $27-33 p g$ \\
\hline \multicolumn{3}{|l|}{ S. Iron studies } \\
\hline Serum ferritin(ug/L) & Normal or slightly reduced & $50-200 u g / L$ \\
\hline Serum iron(mg/dl) & Normal & $50-150 \mathrm{mg} / \mathrm{dl}$ \\
\hline TIBC(ug/L) & Normal & 300-360ug/L \\
\hline Transferrin saturation $(\%)$ & $30-40 \%$ & $30-50 \%$ \\
\hline Peripheral smear & $\begin{array}{l}\text { Marked Hypochromia and microcytic, mild } \\
\text { Anisopoikilocytosis, RDW normal. }\end{array}$ & \\
\hline \multicolumn{3}{|c|}{ Hemoglobin chromatography or electrophoresis } \\
\hline $\mathrm{HbA}\left(\alpha_{2} \beta_{2}\right)$ & $0-80 \%$ & $(96-99 \%)$ \\
\hline $\operatorname{HbF}\left(\alpha_{2} \gamma_{2}\right)$ & $20-100 \%$ & $(<1 \%)$ \\
\hline $\mathrm{HbA}_{2}\left(\alpha_{2} \delta_{2}\right)$ & $\uparrow 3.6-8.0 \%$ & $(<3.5 \%)$ \\
\hline Partner Testing and baselir & $\begin{array}{l}\text { ac, hepatic, endocrine, evaluation is recomm } \\
\text { repeated in each trimester. }\end{array}$ & st visit and should be \\
\hline
\end{tabular}

Management- Current recommandations are - Prevention of complications and early detection \& management of complications during pregnancy. Tretment is essential prevention of complications. Currently limited options are avalaible for management in pregnancy. A multi disciplinary team approach is required to manage these patients during pregnancy involving obstetrician, pediatrician, Fetal medicine specialist, physician, hematologist, general surgeon and endocrinologist $[1]$.

\section{Blood Transfusion 2. Iron chelation therapy 3. Splenectomy 4. Stem cell transplantation}

Preconceptional counseling includes genetic counseling of parents (carriers) regarding how thalassemia affects pregnancy and risk of inheritance of disease to babies. Carrier state of parents may be detected by molecular genetic testing. Prenatal diagnosis with Chorionic villous sampling, amniocentesis and cordocentesis is possible. In case of IVF, preimplantation genetic diagnosis (PGD) for screening of hemoglobinopathies is recommended. Daily tablet Folic acid is required 3 months before conception and during antenatal period to prevent neural tube defects, because folic acid deficiency occurs due to bone marrow hyperactivity and poor absorption [3]. During her ANC visits, maternal surveillance should be done with routine 
investigations along with TSH, ECG, and oral glucose tolerance test. Hemoglobin should be evaluated on each ANC visit and $\mathrm{Hb}$ should be maintained $\geq 10 \mathrm{~g} / \mathrm{dl}$.

If it falls to $<10 \mathrm{~g} / \mathrm{dl}$, blood transfusion should be done. Prophylactic transfusions may be considered in patients with history of multiple vaso-occlusive episodes and poor obstetric outcome. Blood transfusion necessary during pregnancy, because of anemia increase incidence of IUGR, due to hypoxia and oxidative stress [2].

Iron chelating drugs modify fetal $\mathrm{Hb}$ production, modest increase $\mathrm{HbF}$ level by increasing $\gamma$ chain synthesis. HbF increased level help in $\beta$ globin chain synthesis and improve anemia,decrease oxidative stress, ineffective erythropoiesis is also decreased.

Chelation therapy with deferoxamine in preconceptional period and along with transfusions can reduce iron overload which can lead to pregnancy complications. A study done by singer \& Vicninsky on 40 pregnant patients on iron chelating agent like Deferoxamine, did not reported any side effects or teratogenecity. They concluded, chelation therapy in preconception period improve fetomaternal outcome.

Desferroxamine (Dose-20 mg/kg/day) is the only chelating agent that can be used safely in second \& third trimesters of pregnancy. It has a teratogenic potential and should not be used in first trimester. Patient should avoid smoking and be euthyroid, euglycemic before pregnancy.

Post-splenectomy patients should receive vaccination with hepatitis B, haemophilus influenzae (type B) and meningococcal C vaccine

Antenatal fetal surveillance by USG (early scan, 7-9 week, 11-14 weeks), serial growth monitoring (every 4 weeks after 32 to 34 weeks), biophysical score once a week, Doppler ultrasound every fortnightly is recommended to detect FGR early.

Labor \& delivery managed in same way as a cardiac disease. Epidural analgesia is ideal for labor \& delivery. Avoid circulatory overload to prevent pulmonary edema. Continuous CTG monitoring is mandatory during labor. Aesspos et al concluded that mode of delivery should be indivudualized [7].

A study done by Nassar et al (2006), 5 patients of thalassemia intermedia with pregnancy are reported in last 10 yrs.

Table No 3: Nassar et al study of 5 patients of thalassemia intermedia

\begin{tabular}{|c|c|c|c|c|c|c|c|}
\hline Patient & Age & Parity & $\begin{array}{c}\text { HbF } \\
\mathbf{( \% )}\end{array}$ & $\begin{array}{c}\text { H/o Blood } \\
\text { transfusion }\end{array}$ & Splenectomy & $\begin{array}{c}\text { Complications } \\
\text { FGR-1,IUFD-2 }\end{array}$ & $\begin{array}{c}\text { Fetomaternal } \\
\text { outcome NVD } \\
\mathbf{- 1 , L S C S - 2}\end{array}$ \\
\hline 1 & 28 & G2 & 17.5 & 12 yrs & Preconception & 2 & 1 \\
\hline 2 & 30 & G3 & 17.7 & $\begin{array}{c}\text { Previous } \\
\text { pregnancy }\end{array}$ & Postpartum & 1 & 1 \\
\hline 3 & 34 & G2 & 58.0 & Childhood 5 yrs & Preconception & 1 & 1 \\
\hline 4 & 20 & G1 & 95 & - & Postpartum & 1 & 2 \\
\hline 5 & 26 & G2AI & 80 & - & - & - & 2 \\
\hline
\end{tabular}

Study shows obstetrics complications increased in pregnant patients with thalassemia intermedia. Nassar et al. reported high incidence of IUGR (60\%). They concluded, these patients needs close \& regular ANC visits and serial USG for fetal surveillance to detect FGR early [2.9].

Thalassemia per say is not an indication of cesarean section and active management of third stage of labor should be done. Routine blood transfusion therapy is not indicated becausen of heterogenecity of disease. Transfusion help in prevention from growth retardation hypersplenism, recurrent infections [7, 9]. Risk of venous thrombosis inceased to 30$40 \%$ compare to general population within 10 years due to chronic hypercoagulable state [10, 11]. Hyperslenism and splenomegaly associated with abnormal RBC in thalassemia intermedia that leads to haemolytic anemia [12]. 
Post-partum care - Exclusive breastfeeding should be encouraged. Thromboprophylaxis after cesarean delivery required for 6 weeks because of risk of DVT is $40 \%$ and it is more in post-splenectomy patients [4]. Blood transfusion and chelation therapy with desferrioxamine is safe during pregnancy.

Bone marrow transplantation indicated only in asymptomatic patients with mild disease. Women should use contraception despite reduced fertility with thalassemia intermedia and there is no contraindication to use of OCPs (can be used but increase risk of thrombosis), POP, implants, LNG-IUD. Sterilization may offer to parous women.

\section{Conclusion}

Multidisciplinary team incorporating genetic counsellar, fetal medicine specialist, hematologist, approach is required for mangement of pregnancy with thalassemia. Management of these patients should be individualized. Strict meticulous monitoring with regular ANC visits \& early management of complications, improve fetomaternal outcome.

\section{Funding: Nil, Conflict of interest: Nil Permission from IRB: Yes}

\section{References}

1. Cappelini MD, Cohen A, Eleftheriou A. Guidelines for the clinical management of thalassemia. $2^{\text {nd }}$ Revised edition. Nicosia (CY): Thalassaemia International Federation; 2008.

2. Anwar H. Nassar, Ihab M. Usta,Johnny B. Rechdan, Suzanne Koussa, Adlette Inati, Taher T. Pregnancy In Patients with b-Thalassemia Intermedia: Outcome of Mothers and Newborns. American Journal of Hematology DOI 10.1002/ajh 2006;81:499-502.

3. Cappellini MD, Musallam KM, Poggiali E, Taher AT. Hypercoagulability in non- transfusion- dependent thalassemia. Blood Rev. 2012 Apr;26 Suppl 1:S20-3. doi: 10.1016/S0268-960X(12)70007-3.

4. Royal College of Obstetricians \& Gynaecologists. Management of beta thalassaemia in pregnancy. Green-Top Guideline No. 66. London : RCOG;2014.
5. Weatherall DJ. Pathophysiology of thalassaemia. Baillieres Clin Haematol. 1998 Mar;11(1):127-46.

6. Olivieri NF. The beta-thalassemias. N Engl J Med. 1999 Jul 8;341(2):99-109.

7. Olivieri NF. Reactivation of fetal hemoglobin in patients with beta-thalassemia. Semin Hematol. 1996 Jan; 33(1):24-42.

8. Aessopos A, Karabatsos F, Farmakis D, Katsantoni A, Hatziliami A, Youssef J, Karagiorga M. Pregnancy in patients with well-treated beta-thalassemia: outcome for mothers and newborn infants. Am J Obstet Gynecol. 1999 Feb;180(2 Pt 1):360-5.

9. Karagiorga-Lagana M. Fertility in thalassemia: the Greek experience. J Pediatr Endocrinol Metab. 1998;11 Suppl 3:945-51.

10. Cappellini MD, Robbiolo L, Bottasso BM, Coppola R, Fiorelli G, Mannucci AP. Venous thromboembolism and hypercoagulability in splenectomized patients with thalassaemia intermedia. $\mathrm{Br} \mathrm{J}$ Haematol. 2000 Nov; 111(2):467-73.

11. Eldor A, Rachmilewitz EA. The hypercoagulable state in thalassemia. Blood. 2002 Jan 1;99(1):36-43.

12. Moratelli S, De Sanctis V, Gemmati D, Serino ML, Mari R, Gamberini MR, Scapoli GL. Thrombotic risk in thalassemic patients. J Pediatr Endocrinol Metab. 1998;11 Suppl 3:915-21.

\section{How to cite this article?}

Meena P, Jain S, Lakha V, Rajaram S, Goel N. Pregnancy in patients with thalassemia intermedia: A rare case report. Obs Rev: J obstet Gynecol 2016;2(2):17-21. doi: 10.17511/joog.2016.i02.05. 